Revista de Ensino em Artes, Moda e Design

Dossiê 6

A modelagem integrada ao projeto de Moda no âmbito do ensio

\title{
ASPECTOS DA MODA NO ESPAÇO ESCOLAR: INCLUSÃO, IDENTIFICAÇÃO E EXCLUSÃO
}

Fashion aspects in school space: inclusion, identification and exclusion

\section{Aspectos de moda en el espacio escolar: inclusión, identificación y exclusión}

\section{Laise Ziger $^{1}$}

Edivaldo José Bortoleto²

\footnotetext{
${ }^{1}$ Discente do Programa de Pós-graduação stricto sensu em Educação da UNOCHAPECÓ. Bacharela em Design de Moda pela UNOCHAPECÓ. Bolsista da Fundação Universitária do Desenvolvimento do Oeste - FUNDESTE. Integrante do Grupo de Pesquisas Desigualdades sociais, diversidades socioculturais e práticas educativas. Lattes: http://lattes.cnpq.br/2608044930654865. Orcid: https://orcid.org/0000-0001-6730-6096. Email: laiseziger@unochapeco.edu.br

2 Doutor em Educação (UNIMEP) e Doutor em Comunicação e Semiótica (PUC-SP). Mestre em Filosofia da Educação (UNIMEP) e Graduado em Filosofia (PUC). Lattes: http://lattes.cnpq.br/4348928198416364. Orcid: https://orcid.org/0000-0002-7748-8361. Email: ejbolto@@unochapeco.edu.br
} 


\title{
Resumo
}

O presente artigo deriva de um Trabalho de Conclusão de Curso, o qual teve como objetivo analisar os signos da moda presentes no ambiente escolar, compreendendo de que forma a mesma é percebida e, dessa forma, estabelecer possiveis caracterizações de exclusão, identificação e inclusão. Nesse sentido, o estudo classificou-se como sendo de natureza aplicada e compreendeu-se como uma pesquisa qualitativa e exploratória, transcorrendo em um viés de Moda, Semiótica Peirceana e Educação. Os resultados possibilitaram o entendimento de que a moda se materializa no espaço da escola como um meio de comunicação, pois é por ela que os estudantes se reconhecem como parte do ambiente. Bem como a moda é mediadora de relações dentro desse espaço.

Palavras-chave: Moda; Espaço Escolar; Comunicação.

\begin{abstract}
This article derives from a course conclusion paper, which aimed to analyze the signs of fashion present in the school environment, understanding how it is perceived, establishing possible characterizations of exclusion, identification and inclusion. In this sense, the study was classified as applied in nature, and was understood as a qualitative and exploratory research, taking place in a bias of Fashion, Peircean Semiotics and Education. The results showed that fashion materializes in the school space as a means of communication, because it is through it that students know each other as part of the environment. As well as fashion mediates relationships within this space.
\end{abstract}

Keywords: Fashion; School space; Communication.

\section{Resumen}

Este artículo deriva de un documento de conclusión del curso, cuyo objetivo fue analizar los signos de la moda presentes en el entorno escolar, comprender cómo se percibe y establecer posibles caracterizaciones de exclusión, identificación e inclusión. En este sentido, el estudio se clasificó como aplicado en la naturaleza, y se entendió como una investigación cualitativa y exploratoria, que tiene lugar en un sesgo de la moda, la semiótica de Peircean y la educación. Los resultados mostraron que la moda se materializa en el espacio escolar como un medio de comunicación, porque es a través de él que los estudiantes se conocen como parte del entorno. Así como la moda media las relaciones dentro de este espacio.

Palabras-clave: Moda; Espacio escolar; Comunicación 


\section{INTRODUÇÃo}

Os assuntos abordados no estudo fundamentam-se na moda como forma de comunicação não verbal, partindo da observação do vestuário e afins, buscando compreender se a comunicabilidade, dentro do ambiente escolar, pode resultar em algum tipo de relação, a partir da identificação dos grupos presentes no ambiente. Nesta perspectiva, o estudo teve como objetivo analisar de que forma a moda é percebida dentro do ambiente escolar e se pode caracterizar-se como um fator de exclusão, identificação e inclusão. Dentro do objetivo geral, os seguintes objetivos específicos foram definidos: observar no ambiente escolar as diferentes formas de comunicação através do estudo e interpretações de signos da moda presentes nos locais; compreender de que forma os alunos percebem a utilização do uniforme ou o não uso do mesmo; aplicar a Semiótica como método para análise dos signos relacionados à moda e ao ambiente escolar.

Vale ressaltar que este artigo é um resumo sintetizado do Trabalho de Conclusão de Curso para obtenção do título de bacharel em Design de Moda. E justifica-se pela importância de compreender esses dois campos epistemológicos (moda e educação) no sentido que, ambas as áreas auxiliam na compreensão da história, da cultura e da sociedade, transcorrendo em um mesmo viés com a finalidade de contribuir para a formação do indivíduo.

Diante disso, nota-se que a experiência escolar pode sofrer influências devido ao comportamento, à expressão e à identidade dos sujeitos, neste caso, os alunos. $O$ vestuário, que é uma forma de expressão, "compõe, juntamente com outros atributos pessoais, o perfil das pessoas, inclusive, refletindo estados de espírito" (RAMOS, 2006, p. 5). Por isso, há a necessidade de perceber os estudantes para que se compreendam os processos e fenômenos que ali ocorrem.

Todos vivenciam experiências escolares no decorrer da vida, e inserem-se em grupos que contêm informações não verbais presentes na linguagem e que comunicam moda. Nessa lógica, o estudo sobre a moda no ambiente escolar por meio da Semiótica torna-se instigante e de certo modo inovador, uma vez que existem poucos estudos nessa perspectiva.

No que diz respeito à metodologia, este estudo apresenta-se como pesquisa qualitativa, de modo que as soluções passaram pela pesquisa bibliográfica, para compreensão teórica. Após, os dados foram coletados por meio de pesquisa de campo realizadas a partir da observação, relatados em diário de campo, bem como da realização de entrevistas; todos esses dados foram analisados sob a perspectiva da Semiótica de Charles Sanders Peirce. A coleta das informações ocorreu em uma escola pública, na qual o uso de uniformes é opcional, e em uma escola privada, onde o uso do uniforme é obrigatório.

O estudo perpassa os caminhos da moda, do espaço escolar, bem como da Semiótica Peirceana. 


\section{DESENVOLVIMENTO}

\subsection{Identidade e a Moda}

É por meio de um conjunto de características que o indivíduo se sente pertencente a determinado grupo, além de trazer consigo sua própria individualidade. De acordo com Godart (2010, p.24) "[...] a identidade social não é imediatamente perceptível, exceto em alguns casos específicos, como o momento em que sinais são levados no próprio corpo e são visíveis para todos que observam". Ou seja, são esses sinais que comunicam a identidade dos sujeitos e esses elementos podem estar contidos na moda.

Com relação a isso, Castilho e Martins (2005, p. 55) afirmam que, "Segunda ou primeira pele, a moda significa, discursiviza e manifesta traços de identidade do sujeito, assim como a sua subjetividade". A vestimenta gera códigos específicos e expressa a identidade dos grupos e classes sociais, e é a partir dos sinais identitários que os fenômenos de imitação e diferenciação se desenvolvem.

Esse contexto é afirmado por Costa e Silva (2007, p. 63) quando explicitam que a moda, como um símbolo de comunicação, "[...] tem fundamental importância para que os jovens possam, intersubjetivamente, expressar suas identidades e buscar a construção de seus grupos, conforme seus símbolos de pertencimento". E tudo isso se dá pela forma em que o corpo é adornado ou como ele age, o corpo é o meio pelo qual a moda se manifesta. "Ele, o corpo, constrói assim significados, manifestações textuais que se deixam apreender e significar pelos efeitos de sentido que produzem justamente ao criar uma identidade - para ele mesmo e para a moda" (CASTILHO E MARTINS, 2005, p. 31). E estes são postos em circulação, dando a considerar o corpo como base material que se desenvolve com diferentes formas de linguagens por meio dos gestos, da decoração, da moda, do comportamento; uma mídia que comunica a todo tempo, em todos os espaços.

\subsection{Comunicação: Moda e espaço escolar}

Todos os seres humanos mostram-se dependentes de comunicação, todas as pessoas se comunicam por algum tipo de linguagem. Nesse sentido, Svendsen (2010, p. 21) traz a ideia de que "todos nós temos de expressar de alguma maneira quem somos através de nossa aparência visual". E isso se dá por meio da moda, a qual se apresenta em forma de mídia que utiliza do corpo como suporte para estabelecer uma comunicação não verbal através da linguagem das cores, tecidos e caimentos.

Nessa perspectiva, Costa e Pires (2007) trazem a comunicação para o ambiente escolar e afirmam que a mesma é um processo amplo e complexo que a rotina escolar, por vezes, não consegue abranger. No sentido do vestuário, dos acessórios e afins, apesar de compreenderem a existência destes, há, em alguns casos, o entendimento de apenas o uniforme escolar a comunicar. Porém, sabe-se que qualquer elemento portado transmite algo, as próprias identidades funcionam como símbolos de comunicação que facilitam a aproximação ou afastamento em determinado grupo. 
Dessa forma, percebe-se a moda como uma área que comunica, relacionando-se com a cultura e a sociedade em que está introduzida, isto é, "[...] a noção de comunicabilidade do vestuário está inserida no quadro de uma vida em sociedade onde tudo é comunicação" (RIBEIRO; SILVA, 2012, p. 578). Em toda a história, houve a necessidade de se comunicar de alguma forma, propagando as mais diversas linguagens. Devido a essa necessidade, buscam-se diferentes formas de significação para com o corpo e que este possa ser uma maneira de expressão e comunicação.

\subsection{O ambiente escolar e as "coisas" da escola}

O ambiente escolar é um espaço de convivências e relações, onde os estudantes estão desenvolvendo não apenas suas capacidades em relação à aprendizagem, mas também aprendendo a conviver em sociedade, com pessoas de diferentes culturas e valores. Para que se possa compreender de fato o espaço escolar é necessário perceber os estudantes, uma vez que, segundo Costa e Pires (2007), são eles que trazem para o contexto escolar todo um processo de humanização, seus saberes e culturas. Ainda de acordo com os mesmos autores, os alunos têm no espaço e no tempo em que estão na escola, um momento importante, "trata-se do momento de construção das relações sociais com múltiplas mediações e interesses, voltados para as necessidades pessoais e os vínculos sociais afetivos" (COSTA E PIRES, 2007, p. 63).

Esse espaço é composto por vários elementos: cadernos, carteiras, livros, uniforme. Este último, o uniforme escolar, encontra-se à frente de muitos debates. Com relação ao exposto, Araújo, Silva e Schemes (2013) afirmam que por meio dos uniformes há a padronização e a identificação dos estudantes, e essa prática tem se transformado num elemento fundamental para que haja igualdade para todos, de acordo com um sistema educativo criado. Ainda que segundo Ribeiro e Silva (2012), essa igualdade seja mais prática do que efetiva.

O cenário acima foi baseado no pressuposto de que o uniforme controlaria qualquer ato de discriminação ou possíveis situações constrangedoras para os alunos, devido à forma que estavam vestidos. Porém, de fato, essa realidade não os anulava das possíveis relações. A história e as funções dessa vestimenta se fizeram presente de diferentes formas nas várias épocas, e está longe de ser algo simples, Lonza (2005) expõe essa discussão a ser debatida apenas pelo elemento da uniformização, pois se por um lado esses fardamentos demarcam os corpos, e possivelmente dificultam a liberdade no que diz respeito à construção das identidades, ele também pode contribuir para a estruturação de um sistema mais igualitário e seguro aos jovens.

Por fim, cabe aqui ressaltar que não apenas o uniforme aparece no espaço escolar como signo da moda, existem diversos outros elementos pertencentes como a mochila, o não uniforme, os acessórios, tatuagens, piercing, o esmalte, a maquiagem, o cabelo. Tudo transmite alguma linguagem verbal ou não verbal que comunica aos grupos e ao espaço o que consomem, o que gostam, quem são, seus princípios, suas identidades, que são reveladas por meio da moda. 


\subsection{Linguagem e Semiótica}

As linguagens estão no mundo, logo, tudo está na linguagem. De acordo com Santaella $(1983$, p. 2), a semiótica objetiva investigar todas as linguagens, "[...] ou seja, [...] tem por objetivo o exame dos modos de constituição de todo e qualquer fenômeno como fenômeno de produção de significação e de sentido". Nessa perspectiva, Castilho e Martins (2005) expõem que para a semiótica interessam todos os signos verbais e não verbais, ou seja, a Semiótica é a ciência geral de todas as linguagens, de todos os signos.

Diante disso, a moda, como forma de comunicação não verbal, apresenta-se em uma combinação de signos, formas e cores. Além de explicitar os processos de significação à semiótica, Castilho e Martins (2005, p. 53), afirmam que "[...] a Semiótica, como dissemos, contribui para a exploração de possibilidades de estudos das bases de todas as formas de comunicação, sempre inseridas num contexto com o qual dialogam de modo explícito ou não".

Frente ao exposto, Santaella (2002, p. 5) traz a definição de Peirce, quando afirma o signo ter uma natureza triádica, "Quando a lógica triádica do signo fica clara para nós, estamos no caminho para compreender melhor porque a definição Peirceana do signo inclui três teorias: a da significação, a da objetivação e a da interpretação". E nesse processo definido por Santaella, obtêm-se o processo de semiose: "[...] é a reprodução continuada de um sinal, que é um sinal de outro, e assim sucessivamente" (FERNANDES, 2011, p. 5).

Peirce entente o signo de forma dinâmica por apresentar-se em movimento constante, em que um signo gera outro e assim sucessivamente. Além disso, aborda três categorias universais denominadas primeiridade, secundidade e terceiridade.

A primeiridade apresenta-se como "tudo o que está imediatamente presente à consciência de alguém; é tudo aquilo que está na sua mente no instante presente que vem de maneira imediata, que possui um caráter de apresentação" (SANTAELLA, 1983, p. 9). Apresentando-se como estado de qualidade que nesse "[...] estado-quase, aquilo que é ainda possibilidade de ser, deslancha irremediavelmente para o que já é, e no seu ser ir sendo, já foi. Encontramos no universo do segundo" (SANTAELLA, 1983, p. 10).

Finalmente, terceiridade, que aproxima um primeiro e um segundo numa síntese intelectual, corresponde à camada de inteligibilidade ou pensamento em signos, através da qual o mundo é representado e interpretado. E é na terceira categoria que esse encontra a ideia de signo autêntico ou triádico.

\subsection{Caminhos e método}

O estudo teve início com a pesquisa bibliográfica, em que as principais áreas do conhecimento referentes nesse trabalho (moda, educação e semiótica) permitem uma tríade assim como a Semiótica peirceana nos propõe. Cabe aqui ressaltar os principais autores utilizados: Godart, na área de sociologia da Moda; Lucia Santaella, que traz a Semiótica de Pierce; e Furio Lonza, relacionado à questão da escola e a 
uniformização.

A partir do conhecimento dessas áreas construiu-se o embasamento necessário para o desenvolvimento da pesquisa de campo, que se deu por meio de entrevistas e diário de campo.

As entrevistas ocorreram com uma amostragem de seis participantes por escola, três meninos e três meninas, totalizando doze entrevistados (a escolha da amostragem foi baseada no estudo da Semiótica de Peirce, trazendo a ideia de tríades). Estes procedimentos da pesquisa foram executados em uma escola particular e em uma escola pública, ambas situadas na área urbana da cidade de Chapecó - SC, e que possuem um número considerável de alunos no ensino médio os quais são oriundos não apenas do centro, mas também dos bairros da cidade.

O diário de campo foi relatado por meio da observação e análise dos signos através de um diagrama que leva em consideração as categorias universais e as tricotomias dos signos e dos argumentos da Semiótica Peirceana.

\subsection{Resultados e Discussões}

A partir do diário de campo foi possível visualizar os signos presentes naqueles ambientes, despertando um olhar mais sensível e aos poucos compreendendo suas significações. As entrevistas permitiram um entendimento mais eficiente da percepção dos indivíduos pesquisados quanto aos elementos analisados. Por meio da pesquisa de campo foi possível perceber a percepção dos estudantes no que diz respeito ao uso ou não uso do uniforme escolar.

Nesse sentido, observou-se que a maior parte dos estudantes compreende o uso do uniforme de maneira positiva, no sentido de sentirem-se mais seguros caso precisem ser identificados em situação de perigo ou inibindo que estranhos adentrem o espaço. Bem como há uma maior praticidade e economia, pois com o uso do uniforme os estudantes não precisam utilizar outras roupas.

Apenas um dos entrevistados descreveu realmente não gostar do uniforme por se sentir preso, não ter liberdade de exibir sua personalidade, seus gostos. Porém, principalmente na escola pública, cujos alunos relataram pontos positivos na utilização do uniforme, a maioria dos entrevistados não faz uso do mesmo. Presume-se que os estudantes entendem a importância da utilização do uniforme, mas esteticamente, acabam optando por não utilizar.

Percebeu-se que os estudantes, apesar de não usarem uniformes acabam se uniformizando com camisetas que fazem referências a filmes, jogos e desenhos. Essas peças acabam sendo o mesmo elemento da camiseta do uniforme dos demais, porém transmitem outras informações para os mesmos. Enquanto as camisetas do uniforme comunicam a qual instituição de ensino o indivíduo pertence, as camisetas estampadas explicitam os gostos e as referências de consumo destes estudantes.

Complementando essa uniformização espontânea, os estudantes acabam utilizando os mesmos tecidos como malhas, moletons e jeans, sendo que na maioria das vezes, peças como a legging e a calça jeans. Vale ressaltar que as lavagens do jeans também se diferenciam, assim como as cores das leggings. Desta forma, pode-se 
observar os grupos, e o que os seus integrantes têm em comum, isto acaba sendo evidenciado por um dos entrevistados quando relata vestir calças pretas assim como seus amigos.

Outro elemento que contribui para essa uniformização coletiva é o uso do tênis, com modelos e cores diferentes, utilizado pelos alunos de forma massiva em ambas as escolas. Diante disso, percebeu-se que estes estudantes, principalmente os do ensino privado, onde é obrigatória a utilização do uniforme, acabam fazendo uso de acessórios para se diferenciarem uns dos outros.

Por meio dos signos da moda foi possível perceber as diversas comunicações existentes no espaço escolar. Além disso, os participates demonstraram adaptar-se às limitações impostas pelas instituições de ensino, no sentido que em ambas as escolas os mesmos expõem sua personalidade. No ensino público, de maneira mais efetiva pela liberdade que lhes é dada acerca da vestimenta, e no ensino privado também, apesar do uso obrigatório do uniforme, os estudantes conseguem manifestar sua personalidade por meio de outros elementos, ou seja, a maioria se sente bem ou nem percebe que está se moldando a partir do que é permitido.

\section{CONCLUSÃO}

Foi perceptível a materialização da moda como um mecanismo de comunicação nos espaços de instituições de ensino, sendo um fator primordial para que exista a manifestação das identidades gerando a diferenciação entre os indivíduos, mas o agrupamento entre os semelhantes. Nesse sentido pode-se afirmar que a moda é mediadora de relações dentro do ambiente escolar, e que se apresenta de maneira essencial no que diz respeito à comunicação entre os estudantes.

Os signos da moda tèm uma finalidade muito importante para que exista a identificação entre eles. Assim como afirma Godart (2010, p. 24), "a moda, portanto, nutre-se desses sinais identitários, pois é a partir deles que se desenvolvem seus fenômenos fundamentais de imitação e diferenciação". Sendo assim, entende-se que existem inúmeros signos da moda, e que isso gera o aparecimento de novos grupos, reduzindo os possíveis casos de exclusão.

Compreendeu-se que a escola não pode ignorar a comunicação existente entre os estudantes, pois é dessa forma que eles contribuem para a construção coletiva e não apenas para o cumprimento de regras impostas. Nesse espaço deve haver respeito ao próximo, liberdade de expressão e de construção social e identitária dos sujeitos; é nessa perspectiva que a moda se apresenta como uma parte intrínseca da constituição dos sujeitos.

Cabe aqui ressaltar que, considerando tamanha a relevância e abrangência da temática, torna-se necessário o desenvolvimento de estudos que abarquem outros fatores da moda nesse espaço, ou, até mesmo, outras materialidades da escola a serem estudadas, trazendo novas realidades para o estudo em questão. ${ }^{1}$

\footnotetext{
${ }^{1}$ Revisado por Poliane Dias Fritsche. Graduada em Letras pela Universidade Regional Integrada do Alto Uruguai e das Missões - URI - Campus Erechim; Especialista em Leitura, análise, produção e reescritura textual pela mesma Universidade. Contato: polianefm@gmail.com
} 


\section{REFERÊNCIAS}

ARAUJO, D. C. de; SILVA, C. E. da; SCHEMES, C. A ressignificação do uniforme escolar na contemporaneidade: identidade e representação. Cadernos do Tempo Presente, n. 13, jul./set. 2013, p. 49-59. Disponível em: https://pdfs.semanticscholar.org/7a9b/ bff3db711af3cff495610ac7a96f2c651437.pdf. Acesso em: 10 nov. 2017.

CASTILHOS, K.; MARTINS, M. M. Discurso da moda: semiótica, design e corpo. São Paulo: Editora Anhembi Morumbi, 2005;

COSTA, A. G. da; PIRES, G. de L. Moda/indumentária em culturas juvenis: símbolos de comunicação e form ação de identidades corporais provisórias em jovens do ensino médio. Conexões, v. 5, n. 1, nov. 2007. Disponível em: https://repositorio.ufsc.br/ xmlui/handle/123456789/89073. Acesso em: 13 out. 2019.

FERNANDES, J. D. C. Introdução à Semiótica. In: A. C. de S. ALDRIGUE; J. E. R. LEITE. (Org). Linguagens: usos e reflexões. João Pessoa: Editora da UFPB, 2011. Disponível em: http://www.cchla.ufpb.br/clv/images/docs/modulos/p8/p8_4.pdf. Acesso em: 11 out. 2019.

GODART, F. Sociologia da moda. São Paulo: Editora Senac, 2010.

RAMOS, S. P. Moda e consumo: personificação das coisas e coisificação das pessoas, 2006. Disponível em: http://www.coloquiomoda.com.br/coloquio2017/anais/anais/ edicoes/2-coloquio-de-moda-artigos.php. Acesso em: 13 out. 2019.

RIBEIRO, I.; SILVA, V. L. G. da. Das materialidades da escola: o uniforme escolar. Educação e Pesquisa, v. 38, n. 3, p. 575-588, jul./set. 2012. Disponível em: http://www. scielo.br/scielo.php?script=sci_arttext\&pid $=$ S1517-97022012000300003. Acesso em: 12 out. 2019.

SANTAELLA, L. Semiótica aplicada. São Paulo: Pioneira Thomson Learning, 2002.

SANTAELLA, L. O que é semiótica? São Paulo: Editora Brasiliense, 1983.

SVENDSEN, L. Moda: uma filosofia. Rio de Janeiro: Zahar, 2010

Recebido em: 21/10/2019

Aceito em: 03/02/2020 